\title{
Conceptual blending in English and Serbian question-and-answer jokes: cultural transfer issues
}

\author{
Predrag Niketić \\ University of Niš, \\ predrag.niketic@znrfak.ni.ac.rs
}

\begin{abstract}
This paper analyzes English and Serbian question-and-answer jokes using the cognitive linguistic theoretical framework of conceptual blending, which relies on mental spaces as cognitive packets of information used to interpret the world around us and within us. The analysis is used to illustrate how culture influences humour: specifically, how the AngloAmerican culture, the dominant and best-known foreign culture in Serbia, is used as a basis of jokes in English as well as in Serbian. It is shown that the jokes in English can work on a nonEnglish-speaking Serbian recipient culturally, but only if not impeded by linguistic obstacles, such as untranslatable puns. The selected Serbian jokes illustrate intercultural merging, as they use elements from both Anglophone and Serbian pop cultures to create humour that is difficult to transfer back to Anglophone audiences, but now due to linguistic as well as cultural transfer issues. These issues revolve around humour translation, which is made difficult by linguistic aspects, cultural aspects, or both. Conceptual blending and the mental spaces involved provide a useful tool for adapting cultural/linguistic barriers to obtain more or less workable joke translations.
\end{abstract}

Keywords: jokes, culture, conceptual blending, English, Serbian

\section{Introduction}

This paper discusses verbal humour, which is entirely based on language, including both spoken and written, i.e. any humorous content expressed through the use of language. What language and humour have in common is that they are both distinctively human features. Verbal communication and laughter have been inseparable human traits since as early as the first human communities. Walter Nash considers humour "a specifying characteristic of humanity", comparing it to "the power of speech, the mathematical gift, [and] the gripping thumb" (Nash 1985: 1). Despite the numerous scientific theories and schools of thought that view language and laughter in different ways (e.g. in terms of innateness, mimicry, or social conditioning) and from within different disciplines, such as psychology, biology, sociology, anthropology, etc., ever since the times of Plato and Aristotle, there has not been a satisfactory definition that would resolve the looming issue, in Raskin's terms, of "what is funny, why it is 
funny, how it is funny, when it is funny, and to whom it is funny" (Raskin 1998: 3). Although over a hundred theories of humour were documented some 50 years ago (Lyttle 2001), the modern study of humour is founded on a generally accepted division into three major groups of theories, first proposed by Monro (Monro 1963) - superiority theories, release/relief theories, and incongruity theories (see also Raskin 1985: 31-40; Monro 1988; Attardo 1994: 47-50; Krikmann 2006: 27-28; Smuts 2006; Mulder \& Nijholt 2002). It should be noted that, despite their designations as theories, these are still only approaches to the study of humour (Smuts 2006: §1b; Yus 2016: 65).

Since the topic of this paper pertains to conceptual blending, which is a theoretical concept that originated within the cognitive sciences, specifically, cognitive linguistics, one group of theories - incongruity theories - is of particular interest. Incongruity was formally introduced into humour studies by psychologist Jerry Suls, who added the resolution of incongruity as another crucial aspect of understanding humour. This triggers the humorous effect, with a strong emphasis on the cognitive process involved (Suls 1972). Other authors have also observed the vital role of cognition in humorous communication. For instance, folklorist Arvo Krikmann regards incongruity theories as "essentially cognitive" because, in the course of humour interpretation, when the recipient reaches a semantic obstacle that creates incongruity, "[t]hen some instantaneous cognitive work will be done to overcome the contradiction and another interpretation that has so far remained hidden can be found" (Krikmann 2006: 27). On the other hand, psychologist Leon Rappoport extends the trifold division of humour theories; he adds cognitive theories as a separate category, while noting that they emphasise the intellectual aspect of humour, as opposed to the emotional aspect highlighted in other theories (Rappoport 2005: 17-18). Thus,

laughter is viewed as the outcome of creative problem solving, an activity that requires some degree of information processing or the mental manipulation of symbolically represented persons or concepts. A simple example is the joke about Moses coming down from Mount Sinai and announcing to the waiting crowd, "I have good news and bad news. The good news is that I got Him down to ten. The bad news is adultery is still in." In order to get the point, you would have to know who Moses was, what the Ten Commandments were about, the meaning of adultery, and the fact that one of the Commandments forbids it. Even after processing these concepts, if you did not think people enjoyed adultery, the joke would make no sense.

(Rappoport 2005: 18)

Serbian linguist Diana Prodanović Stankić has also observed the connection between incongruity theories and cognitive processes by directly referring to incongruity theories as cognitive theories (Prodanović Stankić 2016: 86-89). The cognitive perspective, therefore, gives prominence to cognitive processes that occur quickly, unconsciously, and simultaneously in the human mind, working towards a dynamic construction of meaning.

The notion of incongruity and the cognitive aspect in humour interpretation has been the cornerstone of linguistic studies of humour, including the pioneering, fully-linguistic theories - the Script-based Semantic Theory of Humour by Raskin (1985) and the General Theory of Verbal Humour by Attardo and Raskin (1991). However, the study of humour within the cognitive linguistic domain emerged only in the early $21^{\text {st }}$ century, owing primarily to the work of Seana Coulson. She drew a connection between the inherently cognitivist concepts of frame-shifting and conceptual blending and humorous communication / understanding of humour (Coulson 2001; Coulson 2002). She even developed a model of language understanding specifically aimed at analysing the interpretation of one-liner jokes, called space structuring (Coulson et al. 2006). The incongruity resolution model from a cognitivist perspective was also explored by Geert Brône and Kurt Feyaerts (Brône \& Feyaerts 2003). There are also studies pertaining to the development of cognitive humour competence in 
children (Schnell 2012) and of social-cognitive skills pertaining to humour in adults (Schnell \& Varga 2012). In Serbian literature, a comparative analysis of English and Serbian humour from a cognitive linguistic perspective can be found in Prodanović Stankić (2016).

The present paper presents an attempt to apply the postulates of conceptual blending theory to the analysis of English and Serbian question-and-answer (Q/A) jokes and to point to specific issues in the understanding of jokes stemming from the linguistic and cultural differences, which also include the translation of English jokes into Serbian.

Q/A jokes have been chosen due to their widespread availability in both online and printed media and their conciseness on one hand, and their quick creation of incongruity and resolution in the joke recipient on the other hand. The latter reason refers to the almost instant triggering of a humorous reaction in the recipient, since instantaneity might be considered a distinctive property of the conceptual blending process. This idea is based on a hypothetical notion that longer narrative jokes, which take longer to establish a context, increase the recipient's expectancy of incongruity, thus leading to an automatic cognitive attempt to decipher the joke resolution even before receiving the actual punchline. In contrast, the recipient hypothetically does not have sufficient time to cognitively decipher the punchline before actually receiving it. Furthermore, if longer jokes are told by a bad joke teller, the punchline might inadvertently be hinted at, or even revealed, earlier; however, with shorter jokes, the chance of such a humoristic faux pas decreases. Even though both longer and shorter joke forms require percentiles of seconds for the dynamic construction of meaning, the shorter jokes seemingly provide a more prominent sense of immediacy.

The following section briefly describes the general tenets of conceptual blending theory.

\section{Conceptual blending theory}

Conceptual blending, or conceptual integration, was first introduced to the study of grammar by Gilles Fauconnier and Mark Turner around the turn of the $21^{\text {st }}$ century (Fauconnier \& Turner 1998, 2002; Turner 2015). Conceptual blending represents mental or cognitive processes that quickly, unconsciously, and simultaneously, i.e. dynamically, construct meaning. It actually offers an explanation as to how we are able to understand phrases such as Irish coffee, break the ice, and hit the books, or morphological blends (blend is also the name of the result of conceptual blending) such as emoticon or staycation.

The conceptual blending theory is based on the notion of mental spaces, which constitute "small conceptual packets constructed as we think and talk, for purposes of local understanding and action. They are interconnected, and can be modified as thought and discourse unfold" (Fauconnier \& Turner 1998: 1). The elements of mental spaces are organized in the form of frames. According to Coulson, frames are "representational structures to structure our experience of ongoing activity. Moreover, frames serve as interpretive resources for socially defined activities, giving meaning to things that would otherwise be meaningless" (Coulson 2001: 35). It should be noted that frames do not correspond fully to objective reality, but are rather idealized versions of reality manifesting as variations on prototypes (Prodanović Stankić 2016: 104). Kövecses metaphorically describes mental spaces as "small lightbulbs lighting up in the brain/mind. The area 'lit up' corresponds to an activated mental space" (Kövecses 2006: 250). Conceptual blending requires at least four mental spaces: two input spaces, a blended space, and a generic space. The conceptual blending network is usually represented in the form of a diagram (Figure 1), where mental spaces are represented by circles or ellipses. The generic space contains general and abstract elements (the yellow dots), which encompass all other mental spaces and provide a common frame for the subsequent blending of mental spaces. The input spaces contain concrete interrelated elements. 
The abstract elements from the generic space are projected onto the concrete elements in each input space, represented by yellow dashes in Figure 1.

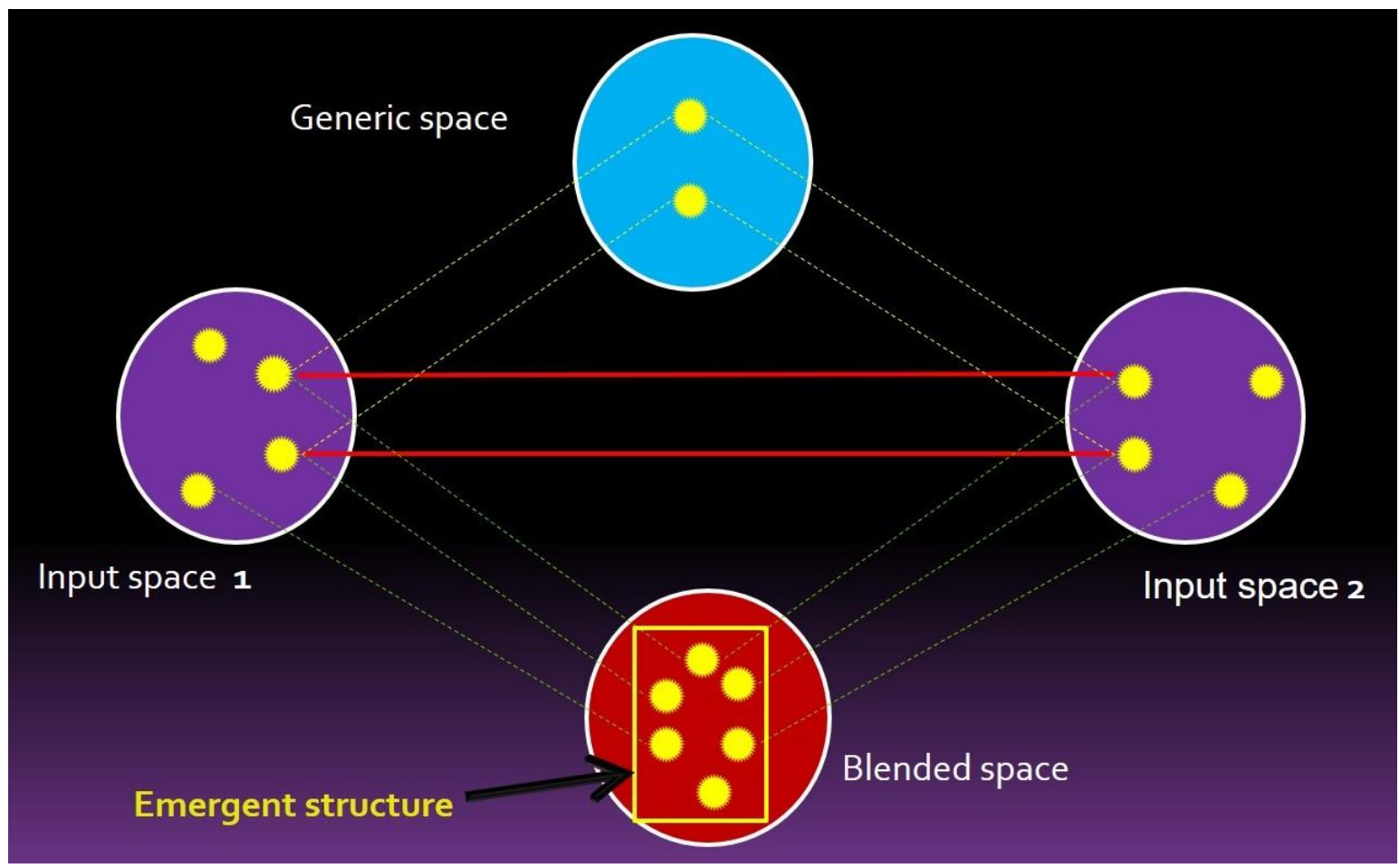

Figure 1. Conceptual blending network. Source: Fauconnier \& Turner 2002: 46 (Redesigned by the author)

Conceptual blending is a process that involves several operations. The first operation is the mapping between the elements from both input spaces, which establishes their equivalent relationship (represented by solid red lines in Figure 1). Equivalence is established according to a number of vital relations, such as identity, change, time, space, and metaphoric or metonymic relations. At least one instance of equivalence is necessary for the combination of elements, their relations, and the input spaces. Only then can the elements be projected from the input spaces into the blended space (green dashes, Figure 1) to produce the emergent structure (yellow rectangle, Figure 1). It needs to be noted that mapping does not occur between all input space elements. Likewise, not all elements are projected from the input spaces into the blended space, which Fauconnier and Turner refer to as selective projection (Fauconnier \& Turner 2002: 29). Different projection combinations are possible, involving elements from both or only one input space, while some elements are not projected into the blended space at all.

The emergent structure often does not correspond to real-world relations, but it is still meaningful to us because the projections bind it to the elements from input spaces, where their meaning does correspond to our general and specific knowledge about the world. Thus, meaning is not restricted to the emergent structure, i.e. the blend, but is constructed throughout the conceptual blending network. The emergent structure is the result of three processes involving the elements of input spaces and their projection into the blended space. The first one is composition, whereby elements from input spaces are combined and connected. The second is called completion, referring to the mental completion of the emergent structural pattern, where people unconsciously call upon their general encyclopaedic knowledge about the world, which is integrated within the memory. The third process is called elaboration and it represents a dynamic, creative, and potentially unlimited elaboration of the emergent 
structural pattern, or "running the blend" (Fauconnier \& Turner 2002: 48). This operation allows us to easily understand metaphorical utterances such as the screenwriters butchered the original book.

The name that can be indirectly tied to conceptual blending is that of Arthur Koestler, whose Buddhist monk riddle was used by Fauconnier and Turner as a means of explaining conceptual blending:

A Buddhist Monk begins at dawn one day walking up a mountain, reaches the top at sunset, meditates at the top for several days until one dawn when he begins to walk back to the foot of the mountain, which he reaches at sunset. Make no assumptions about his starting or stopping or about his pace during the trips. Riddle: Is there a place on the path that the monk occupies at the same hour of the day on the two separate journeys?

(Fauconnier \& Turner 2002: 39)

The solution to the riddle requires the simultaneous entertainment of the monk's ascent and descent, whereby the elements that constitute the monk's climbing the mountain are contained in input space 1, whereas the descent elements are contained in input space 2 . The generic space contains the shared properties of the two input spaces - a person moving along a path from the foot to the summit in an unspecified direction. The blend fuses the two journeys to provide a conceptualization of the monk meeting himself somewhere along the path at a point in time (Fauconnier \& Turner 2002: 41-42).

The riddle was adapted from Koestler's book The Art of Creation (Koestler 1964: 183184), in which the author views human creativity as a result of reacting to the phenomenon he calls "bisociation" (Koestler 1964: 35): this denotes two simultaneous but incongruous ideas or events stemming from different experiential frameworks (see also Krikmann 2006: 28-30 and Coulson 2002: 3). Creativity is born from the resolution of this conflict or bridging of the gap and it manifests in three ways: through humour, science, and art. Fauconnier and Turner did not focus solely on the humour, but rather on Koestler's idea that "creativity involves bringing together elements from different domains" (Fauconnier \& Turner 2002: 37).

The following section explains how conceptual blending works in joke interpretation, with two sub-sections dedicated to English and Serbian question-and-answer jokes, respectively.

\section{Conceptual blending in question-and-answer joke interpretation}

In addition to Coulson $(2002 ; 2005)$, other authors have contributed to the study of humour using the cognitivist and the conceptual blending theoretical framework. Brône et al. (2006) were the first to summarize the current cognitive linguistic approaches to studying humour. Furthermore, Brône (2008), as well as Tabacaru \& Lemmens (2014) used examples from TV shows to expound on the phenomenon of hyper-understanding, a complex schema in interactional humour, first introduced by Veale et al. (2006), who analyzed the cognitive mechanisms of adversarial humour. Hyper-understanding relies heavily on Fauconnier's notion of mental spaces, as well as on the concept of layering (Clarke 1996), and it refers to an exchange in which a second speaker reverses the first speaker's intended meaning by using an alternative meaning for the sake of humour, thus manipulating the original discourse space (Veale et al. 2006: 305; Brône 2008: 2028). Other noteworthy humour-related or humouradjacent topics investigated through mental spaces and blending include advertisements 
(Lundmark 2003; Dynel 2011), talk radio ${ }^{1}$ (Coulson 2005), comics and metaphor (Forceville 2016), and political humour (Delibegović Džanić \& Berberović 2010; 2017).

The process of conceptual blending is shown below using the example of an English joke containing a pun that relies on lexical ambiguity (Figure 2):

(1) If a cat has nine lives, what has more?

A frog - it croaks every day.

The general elements in the generic space - animal, belief, and action - include the elements from the two input spaces: the salient meaning of the verb to croak is to die when it refers to cats and cats are superstitiously believed in many countries to have nine lives; on the other hand, there is no such belief related to frogs, so to croak now has a salient meaning of producing a deep hoarse sound typical of frogs and the non-salient meaning to die. From a strictly semantic perspective, to produce a deep hoarse sound typical of frogs is generally the salient meaning of the verb, but saliency is used here solely in reference to the given joke context, where the generally non-salient meaning becomes salient, as is commonly the case with metaphors. Mapping between two input spaces occurs only between the colloquial meaning of croak=die and it is this meaning that produces incongruity, since the frog "dies" every day and yet, has more lives than a cat. The frog and both meanings of croak are projected into the blended space. In this case, running the blend involves the disambiguation of the concept croak in relation to the frog, which resolves the incongruity and results in a humorous effect. Thus, the humorous effect is achieved through incongruity between two domains of meaning and cognitive operations used to resolve it.

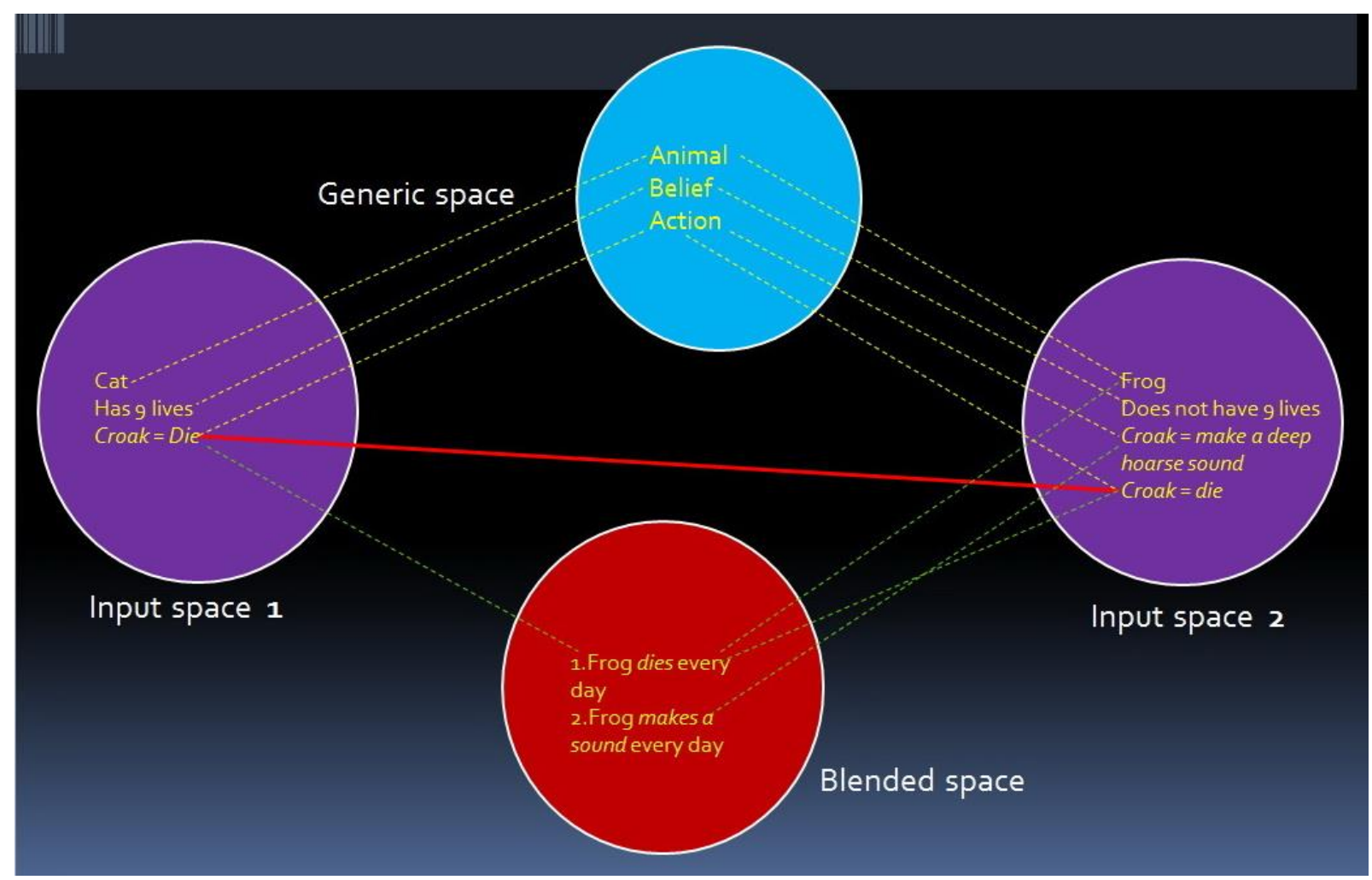

Figure 2. Conceptual blending network of the frog joke. Source: Author

1 The cited author uses "talk radio" as a general term in her article title, but provides examples from a single episode of an American radio talk show. Although the term is broader than radio talk shows (e.g. dedicated talk radio stations), in the present context the two are synonymous. 
The analyzed question-and-answer joke examples contain jokes in both English and Serbian and have been selected thematically, based on their cultural and/or intercultural particularities reflecting the Anglo-American global (pop) cultural domination and its impact on Serbian pop culture, manifested through joke assimilation or adaptation. Jokes specifically targeting ethnic or social stereotypes such as blondes, Scotsmen, Jews, or lawyers (in English jokes) and blondes, policemen (stupid), Montenegrins (lazy), or persons from the town of Pirot (stingy) (in Serbian jokes) are avoided, unless they serve to illustrate a broader cultural context. The idea behind such a selection of jokes for a cognitive linguistic discussion is based on the work of British sociologist Christie Davies, who presented the similarities and differences of humorous ethnic stereotypes in many European countries. In terms of their translation into different languages, he divides ethnic jokes into three categories: transposable, where joke targets are shared; switchable, where joke targets can be easily replaced; and problematic, where joke targets are neither shared nor switchable (Davies 2005: 148). However, Davies' classification covers only jokes in which the humorous effect is achieved by non-linguistic means, i.e. solely through ethnic or social stereotypes. The jokes below include both the sociocultural and linguistic humorous triggers, which is why the focus is on assimilation and adaptation based on conceptual blending, rather than translation in the strictest sense.

All the Q/A jokes have been taken from a variety of online sources (provided after the References section) and cover a variety of topics, as they can be found on multiple websites and even in multiple printed joke collections. They were randomly selected among numerous jokes that contain a cultural reference. Some jokes may be considered outdated, referring to persons or events younger readers might be unfamiliar with; however, this does not change the fact that they were used as jokes at the time their subject matter was current; that is enough for the purpose of this discussion. In addition, each joke is explained, in case someone does not understand the reference. Depending on the source, some of the jokes have a different form, e.g. a different sentence structure, but the punchline remains the same.

\subsection{Analysis of English jokes}

The jokes in English deal with topics with which an average Serbian person should be familiar, as the Anglophone culture has been the dominant foreign culture in the Balkans since the mid- $20^{\text {th }}$ century, mostly due to global prevalence of Anglo-American films and popular music. Nevertheless, even if we presume that all of the joke topics are familiar, it does not necessarily mean that the jokes would work on a Serbian recipient.

(2) Why doesn't Mexico have an Olympic team?

Because everybody who can run, jump and swim is already in the U.S.

In this joke, the question already contains an incongruity since it can be considered common knowledge that Mexico does, in fact, have an Olympic national team. Consequently, the question forces the joke recipient to include a mental input space of a world in which Mexico does not have an Olympic team into the cognitive process, which yields an additional blended space, so the whole joke can be characterized as a hyper-blend according to Coulson (Coulson 2002: 6). A hyper-blend could be regarded as a blend that relies on another blend as an input space. Since hyper-understanding was also mentioned (see Section $\S 3$ above), the difference between a hyper-blend and hyper-understanding should be explicated to avoid potential confusion. Although they share a prefix, they are different in that the former requires a receiving communicator to dynamically construct two or more blends, which are part of the sending communicator's intention, in order to understand the originally intended multi-layered 
meaning. The latter, however, involves the receiving communicator's intervention aimed at altering the originally intended single-layered meaning.

The answer activates the input spaces of the Olympics on one hand and illegal immigration into the United States on the other hand. The mapping of elements is based on analogy, and the elements mapped are Mexican athletes or individuals with advanced physical abilities and Mexican illegal immigrants. The projections are elaborated in the blended space in view of the US political issue of mass illegal immigration from Mexico despite the rigorous measures taken to prevent it, such as border patrols, fences, and, more recently, even walls. In the blend, such obstacles can only be surmounted by people with Olympic-level physical training, with the mass nature of immigration implying that there are no such people left in Mexico anymore.

Even though the joke is fully translatable into Serbian, arriving at the same blend and finding it funny would require that a Serbian recipient be familiar with the attitude of the US government towards illegal immigration from Mexico. Since this is an older joke, it would be fair to assume that at the time of its origin, it would have been understood and enjoyed by fewer Serbians than today, being that the issue has been made prominent by the current US government.

\section{(3) What does Woody Allen call an unborn baby?} A blind date.

The blending process requires an input space containing Woody Allen, known as a person who began a romantic relationship with a woman 37 years younger than him, and the woman in question, namely Soon-Yi Previn. The second input space contains the element "unborn baby". Soon-Yi, Allen's current wife, who was only 19 when they started dating, and an unborn baby are projected into the blended space. The elaboration yields the following blend: Woody Allen has a tendency to seduce women who are so much younger than him that they have not even been born yet. The joke is a fine example of how conceptual blending enables the construction of meaning and establishment of connections by combining temporally distant domains (an unborn baby / a 19-year-old woman). It should be noted that the joke answer blind date is itself a conceptual blend, which also makes this joke a hyper-blend.

Full translation into Serbian is possible, as the phrase blind date also exists in the Serbian language, as a direct translation from English. However, since this topic dominated the news almost 30 years ago, it is questionable whether the joke would work on a younger Serbian audience. Similarly, it is questionable how much of the younger Serbian population is familiar with Woody Allen himself. Thus, the joke did establish cultural contact, but is probably limited to the time when the issue was current. Therefore, it stands to reason that the people who actually witnessed the news would have the relevant mental spaces more readily available.

(4) What do Yoko Ono and Ethiopians have in common? They both live off dead beetles.

The joke question activates two otherwise completely unrelated input spaces: Yoko Ono and Ethiopians. The understanding of the joke requires previous knowledge about Yoko Ono and her role throughout the history of The Beatles and about the fact that famine is a common occurrence in Ethiopia. The joke answer adds a pun to the network. The pun involves the words beetles (insects) and Beatles (the band). The latter is a morphological and, automatically, conceptual blend combining beat and beetles. The two projections are elaborated in the blended space yielding the emergent structure that contrasts Yoko Ono, who 
enjoys all the benefits passed on from her late husband John Lennon, with Ethiopians, who are forced to eat beetles due to a shortage of proper food.

Translation into Serbian is possible even though a lexical pun is involved. The Beatles, as a global phenomenon, were also very popular in former Yugoslavia and were nicknamed liverpulske bube [lit. beetles from Liverpool]. The Serbian translation would thus easily resolve the pun, because the nickname disregards the beat part of the original morphological blend. On the other hand, the joke will not work unless the Serbian recipient is familiar with Yoko Ono; hence, the joke's success depends on how many people in Serbia are familiar with both The Beatles and Yoko Ono, because the two are not necessarily mutually inclusive.

(5) What's green and smells like pork? Kermit the Frog's finger.

The joke answer activates mental spaces containing elements related to the famous TV puppet show The Muppet Show. One input space contains Kermit the Frog, the main character of the show, who is green all over, including his fingers; another one contains pork, referring to regular pig meat. The third input space contains Miss Piggy, another main character from the show and Kermit's girlfriend, who is a pig. The pork and Miss Piggy are mapped metonymically, but only Miss Piggy is projected into the blended space, along with Kermit the Frog, to form the emergent structure with a sexual connotation. The generic space contains elements such as colour, smell, meat, animal, etc.

The Serbian translation does not require any modification, since the joke does not rely on a pun but on a reference to a pop culture phenomenon - The Muppet Show - and its main characters. The show is widely recognizable in Serbia as it used to air frequently on Serbian television from the 1980s to 2000s. Furthermore, the show can be considered a prototypical TV puppet show, as it achieved immense popularity that no domestic puppet show was able to match. The popularity of the show was aided by the catchy and equally famous theme song. The ability of Serbian people to activate the relevant mental spaces to understand the joke is an illustrative example of how Anglophone culture was the dominant foreign culture in Serbian television broadcasting.

(6) How does Michael Jackson pick his nose? From a catalogue.

This is another joke based on a pun that requires disambiguation. The ambiguity of the verb pick activates two input spaces, one with the verb meaning repeatedly pull at something with one's fingers, which is the expected meaning when paired with a nose, and the other with the added meaning choose. Both spaces contain the nose as a part of the human face, but in the second input space, the element is extended to an artificial, surgically altered, body part. This extension is an association to a number of elective surgical procedures to which Michael Jackson subjected himself when he was alive. The mapping between input spaces occurs for the verb pick $=$ pull at something and the natural nose. Similar to joke (5), only the elements from the second input space are projected into the blended space to yield the emergent structure in which the singer chooses his new artificial nose. The humorous effect is presumably achieved on a global scale, because Michael Jackson became a worldwide household name a long time ago; or, from a cognitive perspective, he is contained within the mental conceptual database of most of the world's population.

This joke becomes problematic when translated into Serbian, due to non-corresponding translational equivalents: the meaning repeatedly pull at something with one's fingers corresponds to the Serbian verb čackkati while the meaning choose corresponds to the verb 
birati. Even though the humorous effect can be achieved conceptually in a Serbian recipient, this is not possible on a lexical level, unless a substantial transformation is applied in the translation, for instance Kako Majkl Džekson čačka nos? Onako kako piše u uputstvu za upotrebu (author's translation) [Eng. How does Michael Jackson pick his nose? The way it says in the user's manual], which retains the original frame of nose as a product, rather than a body part. This example illustrates how linguistic elements can affect the humorous transfer of a joke even when there are no cultural obstacles to joke understanding. In addition, it reveals how conceptual blending can be used to help translators deal with puns - by elaborating the relations from mental spaces in a different manner.

(7) What do you get if you cross a black person with an octopus?

I don't know but it would be excellent at picking cotton.

The joke can serve as a perfect example of conceptual blending, since the question itself invokes a fictitious cross, i.e. blend, of two concepts that are 'unblendable'. The first input space contains an octopus, which prototypically denotes an aquatic animal with eight tentacles, this time extended with the element of cotton picking. The second input space contains a person of African origin with dark-coloured skin and two hands, cotton picking, and slavery, since the latter two elements are historically associated. The mapping only occurs for the cotton picking activity. The elaboration of the octopus, the black person, and cotton picking in the blended space yields an emergent structure that has no equivalent in the real world - a being with eight arms picking cotton on a slave plantation. Yet, regardless of the fact that there is no real-life counterpart to the blend, a humorous effect is achieved because humans are able to construct such a blend and to associate it with a hypothetical mental space in which something like that is actually possible. It must be noted, though, that jokes such as this one are often found offensive by the recipients, instead of humorous, but the offensiveness primarily depends on the wider social context and individual emotional traits. Whether someone finds the joke funny or offensive is irrelevant to the discussion at hand, because the interpretive cognitive processes remain the same, i.e. joke recipients from both the "amused" and the "offended" ends of the spectrum understand the punchline, but how it affects them is another issue and one that is beyond the scope of this paper. ${ }^{2}$

The translation of the joke into Serbian already exists online and it should achieve the same humorous effect in Serbian recipients, as American slavery, one of the largest institutionalized slavery systems in recent history, is included in the history curricula of Serbian schools. The familiarity with the topic perhaps goes much wider, with a reference to general oppression and the fight for emancipation. For instance, Serbia was under Ottoman occupation for several centuries, during which many Serbs were enslaved and forced to fight for the Empire, and Serbian people suffered one form of oppression or another throughout the $20^{\text {th }}$ century. Hypothetically, this might facilitate the activation of required mental spaces.

However, in addition to the Serbian translation of the original joke, there is also a fullfledged adaptation, which completely removes slavery from the context:

(7a) Šta se dobije kad se ukrste Leskovčanin i hobotnica? Ne znam, ali ne da bere paprike.

[What do you get when you cross a guy from Leskovac and an octopus?

2 The psychological treatments of humour, including the aggressive variety, are neatly elaborated in Martin (2007). 
I don't know, but it sure can pick peppers.]

Leskovac is a town in southern Serbia famous for its red pepper growing and harvesting. The joke adapts the original elements to create frames that are even more familiar to the Serbian audience. Although some linguistic elements were changed, it is the cultural adaptation that makes the joke uniquely Serbian. The joke relies on the social stereotype of people from Leskovac as pepper growers, but the stereotype is unlikely to offend anyone from Leskovac.

The previous analyses indicate that, barring linguistic obstacles, such as puns, humorous cultural transfer from the dominant Anglo-American to Serbian culture can happen smoothly if the target audience is sufficiently familiar with the receiving cultural information. Owing to a cultural "invasion" from the West after WWII, people in Serbia (and former Yugoslavia) share a substantial amount of pop culture information with the people from Anglophone countries, so they are able to call upon the same cognitive frames and activate the same mental spaces as the latter. Indeed, the shared encyclopaedic knowledge can be hindered by untranslatable wordplay, but the conceptual blending network offers a plausible interpretation of how the linguistic obstacles can be overcome by focusing on different elements from mental spaces to arrive at a satisfactory joke adaptation.

\subsection{Analysis of Serbian jokes}

The Serbian jokes below were selected to illustrate the Anglophone influence on Serbian humour, as this is the dominant direction of the influence between the two cultures - there are rare instances of Serbian culture influencing English-speaking humour (see the end of this section). The jokes considered would not work if translated literally into English, as they merge both linguistic and cultural Anglophone influences with the Serbian language and culture. However, adaptation would make sense in some cases. Literal English translations are provided in square brackets after each Serbian joke, to illustrate the fact that their humorous effect would be lost for an English-speaking audience. Some literal translations preserve certain elements from the source culture, but the punchline and the manner in which the cultural elements are employed remain incomprehensible. The analysis of each joke clarifies these aspects.

(8) Šta je to Dan žena?

Isto što i Noć veštica, samo po danu.

[What is Women's Day?

It's the same as Night of the Witches, only during the day.]

The Night of the Witches is actually the Serbian name for Halloween. This Western Christian festivity with origins in Celtic mythology and traditions, which was brought to the US from Ireland and Scotland, has never been officially observed in Serbia. Yet, in the previous decade, younger Serbian generations began to organize costume parties on 31 October, without observing any Halloween traditions, such as pumpkin carving or trick or treating. The only plausible explanation is the heavy influence of American films and television, in which Halloween is an unavoidable trope. The joke question plays off of this knowledge. One input space contains Night of the Witches, referring to Halloween, the only valid reference before the punchline, where Witches refers to women practising witchcraft, who are usually depicted as women who cast spells and ride broomsticks; another input space contains night of the witches, where night is the period from sunset to sunrise that belongs to witches, with the informal meaning of unpleasant and often ugly women; the third input space contains 
Women's Day, referring to the international holiday celebrating women; and the fourth space contains women's day, with women who are equated with witches and day as the period between sunrise and sunset. The elements women and witches are mapped and projected into the blended space, together with the night from the second input space and the day from the fourth input space. The elaboration yields the emergent structure of women as witches during both day and night, i.e. all the time. Gender disparagement is a global staple of jokes and is culturally present both in Serbia and in Anglophone cultures, whether interpreted as funny or offensive.

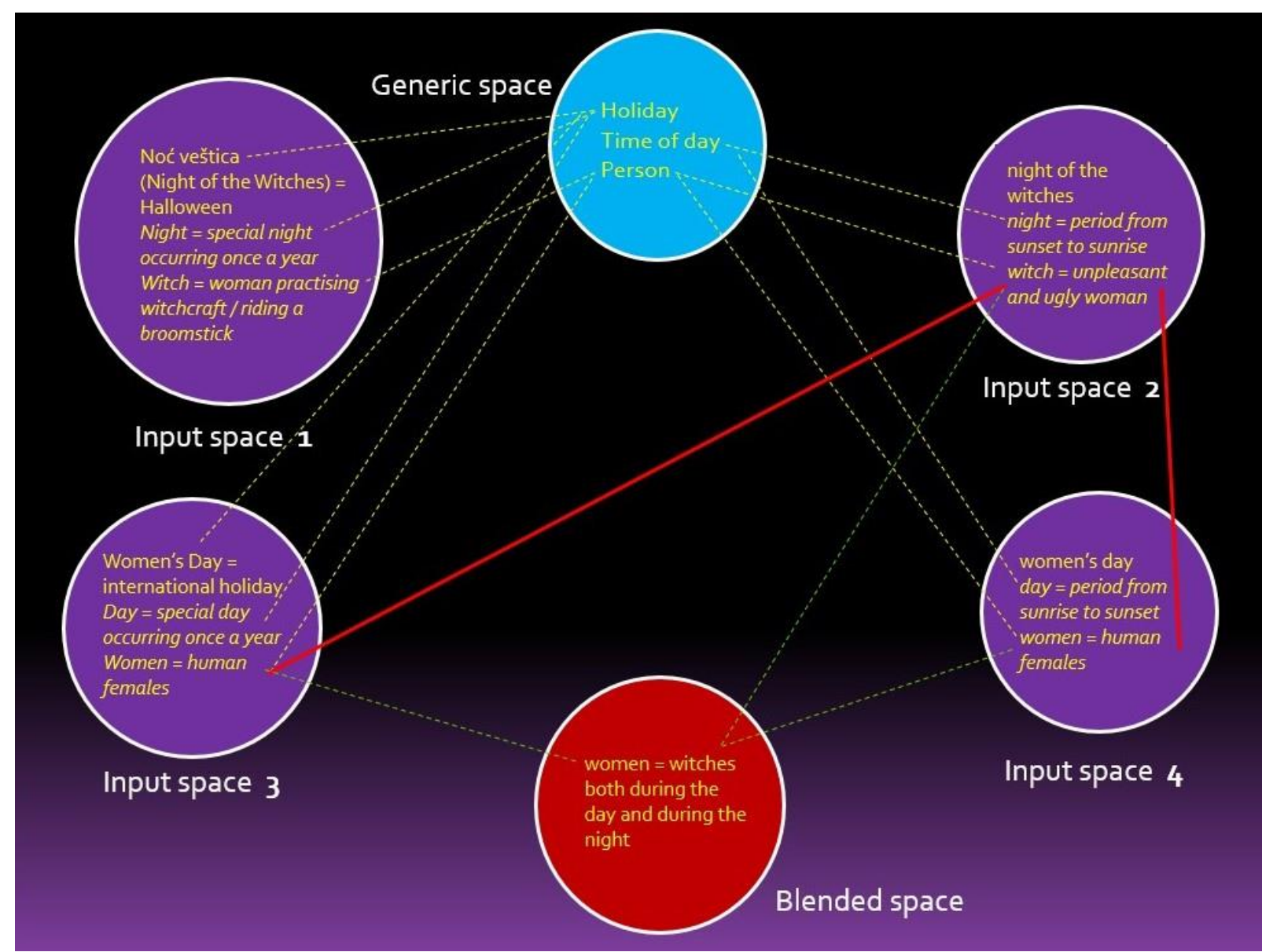

Figure 3. Conceptual blending network of the Women's Day/Halloween joke. Source: Author

However, the English translation works only as an offensive quip, as the reference to Halloween is lost. If the translation were to be adapted to include Halloween, the joke would make no sense. Furthermore, the Serbian name for the holiday reflects the old belief that witches would gather on Halloween, even though witches constitute only a small portion of the modern-day Halloween discourse. Thus, the connection between women and Halloween would be lost in translation, as an English-speaking audience does not have the frame of Halloween $=a$ night of the witches readily available in their encyclopaedic knowledge and would not be able to activate the corresponding mental space. This means that the conceptual blending for the joke is unilateral, because the literal meaning of Serbian Night of the Witches allows for such a connection to be made.

(9) Kako se zove Konanov sin?

Sinan. 
[What is the name of Conan's son?

Son-an.]

The joke relies on a pun, which has been preserved in the above translation. The son's name in the answer is another example of a creative morphological blend consisting of two elements: the Serbian word for 'son' sin and the name Conan. In addition, the name Sinan, Arabic in origin, is also the first name of a famous late Serbian folk singer Sinan Sakić, who is clearly referenced in the joke, being the only celebrity with that name. The interpretation of the joke requires the activation of three input spaces. The first includes Conan the Barbarian, a fictional literary character well-known in Serbia from comic books and film adaptations, and his son Sinan; the second contains the concept $\sin$ as a male descendant, while the third contains the singer Sinan Sakić, whose father is Conan. Conan and Sinan are mapped between the first and third input space and projected into the blended space to form the blend of Conan the Barbarian/father and Sinan Sakić/son. The concept sin is also projected into the blended space providing another blend, $\sin +$ Konan $=$ Sinan, which makes the emergent structure a doubleblend. The conceptual complexity of this simultaneously referential and linguistic joke should ideally intensify the humorous effect.

Of course, even though the joke is partially based on a character from American pop culture, the English translation retaining the original answer name can only go so far, as an English-speaking recipient would have no frame of reference for the Serbian word sin or for the folk singer. The translation offered above would resolve the lexical part of the pun but would be culturally "empty", and might be construed as a bad pun by a native speaker of English. Conan the Barbarian's name was thus used in the joke solely for its lexical similarity to the name Sinan, with its cultural reference bearing only background significance for the punchline. This is an example of an obvious cultural influence being exploited for a different purpose.

\section{(10) Šta je bolje od Red Bull-a?} Red šunke, red sira.

\section{[What is better than Red Bull? A row of ham, a row of cheese.]}

There is another pun at play here, only this time it is interlinguistic. The question activates the first input space containing Red Bull, referring to the widely known brand of energy drink, and the English word red $_{e n}$ with its associated meaning the colour red. The answer activates another input space containing the traditional Serbian meze dish - an appetizer platter with an assortment of cured meat and cheeses - and the Serbian word red s $_{s b}$ with its associated meaning row (as in line, order, or series). Only the forms of $\operatorname{Red}_{e n}$ and $\mathrm{red}_{s b}$ are mapped, not their meanings. Red Bull from the first input space and each element from the second are projected into the blended space and the elaboration, in this case bilingual disambiguation, yields the emergent structure that juxtaposes two kinds of red, an English and a Serbian kind, with the latter being favoured. This is a fine example of how conceptual blending operates interlinguistically.

Blending can also occur beyond the joke if the elements are interpreted metaphorically. In that case, Red Bull stands for the Western culture while ham and cheese represent Serbian tradition. Therefore, culturally speaking, the joke favours Serbian culture and tradition over the more recent, imposing Western culture, represented by both the language and the product.

The joke is bilingual because the original product name Red Bull was retained in Serbian, sometimes transliterated as Red bul, but never translated. The name is easily understood in 
Serbia, where English is taught at school from an early age, not to mention the fact that there is an actual red bull depicted on the packaging. Since the original English name was used only as a tool for emphasizing the Serbian variant, the English translation does not make much sense as a joke. Hypothetically, a better translation would be possible if a food or drink product containing row in its name, if such a product exists on the market, were added instead of Red Bull. Yet, this would be insufficient for a successful cultural transfer, since few English-speaking recipients would be able to activate the mental space of the Serbian traditional appetizer dish.

\section{(11) Kako se zove Cecin doktor? Dr House.}

[What is the name of Ceca's doctor? Dr House.]

Although Ceca is a standard Serbian nickname for the female name Svetlana, if used without a surname in jokes or any other media, it will almost exclusively refer to Svetlana Ražnatović, the most famous Serbian folk singer, as is the case with this joke. The joke relies on the fact that Ceca was sentenced to eight months of house arrest in 2011. The first input space contains Ceca the singer under house arrest and her doctor; the second contains the English word house; and the third contains Dr House, a fictional character from the US TV series House, mentally represented in the form of Hugh Laurie, the actor who played him. The doctor from the first space is mapped analogically with Dr House in the third space, whereas house from the second space is semantically mapped with the house from the first space and phonologically/orthographically with House from the third space. All of the elements are projected into the blended space, where the elaboration yields yet another double-blend: Ceca and Dr House together in her home, and the parallel entertainment of two concepts: Dr House and in-house doctor.

This is another example of a creative cultural and linguistic adaptation into a Serbian framework. The House TV series was very popular in Serbia, which allows for the corresponding mental space to be activated instantly. On the other hand, the required lexical competence of Serbian recipients to understand the word house is sufficiently widespread, as was the case with red in joke (9). As seen from the English translation above, the translated version lacks the cultural aspect, because an English-speaking recipient is highly unlikely to be familiar with Ceca the singer. However, since the butt of the joke relies on the concept of house arrest, the shortcoming in the translation can easily be remedied by replacing the Serbian folk singer with a famous person from the Anglophone world who also was or is under house arrest. Some of the more prominent examples include Bernie Madoff, Robert Downey Jr., Paris Hilton, and Lindsay Lohan. Nevertheless, it is unclear whether the humorous effect of such a joke would be as strong as that of the Serbian version, considering that house arrest is a much more common practice in the US. This is corroborated by the online absence of any such joke. Even if the joke did work equally well in English, the dynamic creation of meaning would still be more complex in the Serbian version due to the addition of bilingual disambiguation to the process of running the blend.

(12) Šta kaže Brus Vilis kada uđe u prodavnicu kompjutera? Daj hard!

[What does Bruce Willis say when he walks into a computer shop? Give me a hard drive!] 
The answer contains a pun that relies on phonological ambiguity. Daj hard is a Serbian imperative verb phrase meaning give me a hard disk drive. This is another case of a hyperblend, because Serbian hard is a reduced form of the noun phrase hard disk, an Anglicism retained in the Serbian language and a conceptual blend in itself. ${ }^{3}$

Phonologically, however, daj hard sounds similar to the English phrase die hard, which is incidentally the title of the film franchise for which the actor Bruce Willis is most famous (translated in Serbian as Umri muški). The first input space contains the actor Bruce Willis, as the character John McClane from the said film, and a request daj hard, asking for a computer hardware component. The second input space again contains Bruce Willis, but now with the command die hard. The mapping occurs between the Bruce Willis from the first space and the one in the second, based on equivalence, and between the phonological forms of imperatives Idaj xardl and /dai ha:(r)dl. All elements are projected into the blended space because the humorous effect relies on both variants being entertained simultaneously in the blend.

A proper humorous translation of the joke into English is clearly difficult. The translation offered above is literal and does not work. The same would apply to a translation of the answer with Die Hard! In the former case, the situation makes perfect sense but is not a joke, and in the latter, the situation makes no sense. Nonetheless, considering that the film title is the part of the joke that was phonologically "assimilated", it would make sense to include it in the translation. This, in turn, would require some modifications of the question part, specifically, replacing the original context with the one in which the answer would come more naturally. This joke is a striking example of interlinguistic adaptation from English to Serbian: a worldfamous Hollywood production was integrated into the Serbian language framework and in a context that has nothing to do with the original but that can be interpreted as funny through conceptual blending.

In general, the influence of Anglophone cultures in Serbia is vast and, consequently, there are a large number of cognitive frames and a large amount of encyclopaedic knowledge shared among the Serbian and the Anglophone people. In this section, an attempt was made to illustrate the ways in which specific concepts from two different cultures and languages can be merged to understand Serbian jokes. Admittedly, the discussion focused on joke understanding and interpretation, but it needs to be specified that conceptual blending operates the same way in joke creation, in that the same mental spaces and relations are manipulated, which is why the joke creator and the joke recipient have to rely on the same conceptual blending network. Despite being partially based on Anglo-American pop culture references, the jokes only work within the Serbian culture, since they add not only linguistic but also cultural elements that are specific to Serbia. In the previous section, all of the analyzed English-language jokes could be considered funny by a Serbian audience that speaks English, which suggests that the linguistic barrier is crucial for the cultural transfer of humour from a dominant to a receiving culture. Accordingly, there does not seem to be any cultural transfer in the opposite direction because there is both a linguistic and a cultural barrier when Serbian jokes are translated into English. Naturally, certain degrees of modification in translation will indeed make some of the jokes work, but usually at the cost of cultural transfer. This is not to say that humorous cultural transfer from Serbia to Anglophone countries is impossible, as evidenced by numerous American jokes making fun of the car Yugo, a distinctly Serbian (or ex-Yugoslav) product. Moreover, the Yugo entered Western, and perhaps even global, pop culture after being used in

${ }^{3}$ For more on Anglicisms in the Serbian language, see Rasulić (2008) and FilipovićKovačević (2011). 
high-budget Hollywood films such as Dragnet (1987), Die Hard: With a Vengeance (1995), or The Nutty Professor (1996), and even having a central role in the film Drowning Mona (2000).

\section{Conclusion}

This paper analyzed English and Serbian verbal humour, specifically question-and-answer jokes, through a cognitivist theoretical framework of conceptual blending. Since humorous communication can be considered a distinctly human trait, this idea can be extended to conceptual blending, as well. Fauconnier and Turner, the originators of the conceptual blending theory, view conceptual blending as an inherent human mental mechanism that allows us to exhibit ever more complex behavioural patterns based on symbolic means of expression, such as language and art (Fauconnier \& Turner 2002). This means that the capacity for conceptual blending influences the human capacity for imagination. That is why Coulson believes that, "[t]hough not all blends are humorous, blending does seem to be an inherent feature of humor" (Coulson 2002: 3), referring primarily to Koestler's bisociation theory (see end of Section 2 above). Accordingly, many cognitive linguists agree that a linguistic theory of humour, aided by theories of metaphor, metonymy, and conceptual blending, can potentially provide a better insight into the creation and interpretation of humour than all of the previous linguistic theories of humour (see Delibegović Džanić \& Berberović 2010: 198). The conceptual blending theory is even perceived as complementary to the theory of conceptual metaphor, the former covering individual instances of ad-hoc meaning construction and the latter covering "recurring patterns in figurative language" (Schnell 2007: 84; see also Grady et al. 1999). However, while there is a justified concern that the overly general nature of conceptual lending theory diminishes its explanatory value (Schnell 2007: 85), its potential is yet to be fully exploited in humour studies and other disciplines.

The discussion also included aspects of contact linguistics, but with regard to both language and culture contact. On the one hand, humour may be regarded as a unique human tool that can be used to fight fears, frustrations, and various forms of discrimination (see Wijewardena et al. 2010; Eriksen 2019), and even to foster friendly relationships among people; on the other hand, it can be used for the exact opposite. Its practical application notwithstanding, humour has an inherent ability to transcend cultural and linguistic barriers, which was hinted at in the joke analysis. As Coulson puts it, "[b]lending and the cognitive abilities that support it are crucial in this respect by enabling us to frame taboo topics in terms and domains which are not taboo" (Coulson 2002: 12). People deal with all the aforementioned issues on a daily basis and they have to expend some cognitive effort to do so. Conceptual blending theory was formulated in a way that can explain the complicated daily mental efforts, including linguistic and cultural contact and humour. Admittedly, any theory that covers such a wide scope of phenomena will be appealing to a researcher. Yet, special care should be taken when applying it, because conceptual blending implies the abstraction of highly complex mental processes, whose mechanisms are yet to be empirically proved. This might steer researchers towards the danger zone of oversimplification. Nevertheless, as long as the human brain and its inner workings have not been fully grasped, such theories are necessary to allow us at least an attempt to answer some of the crucial questions pertaining to humour, e.g. why something is funny.

The paper briefly presented the potential of conceptual blending theory in the study of humour and a variety of sub-topics, such as humour translation and humorous cultural contact. Similar to literature, humour is another aspect of human creativity that often defies translation when in verbal form. However, conceptual blending theory offers a new perspective to translation theory by focusing on different relations between elements of the blending network 
and allowing those elements to be manipulated for the sake of humour. This leaves room for much more extensive and detailed research.

Another topic for further study, which has been omitted from the paper, is the typology of conceptual blending networks, as this discussion focused on the mechanisms as applied to joke interpretation. The various types of conceptual blending networks (see Fauconnier \& Turner 2002, 2007; Filipović-Kovačević 2010) can be used as a framework for joke classification.

\section{References}

Attardo, S. (1994). Linguistic Theories of Humor. Berlin and New York: Mouton de Gruyter. Brône, G. (2008). 'Hyper and misunderstanding'. Journal of Pragmatics 40, pp. 2027-2061.

Brône, G. \& Feyaerts, K. (2003). 'The cognitive linguistics of incongruity resolution: Marked reference-point structures in humor'. University of Leuven, Department of Linguistics preprint no. 205.

Brône, G., Feyaerts, K. \& Veale, T. (2006). 'Introduction: Cognitive linguistic approaches to humor'. Humor 19 (3), pp. 203-228. doi:10.1515/HUMOR.2006.012

Clark, H. H. (1996). Using Language. Cambridge/New York: Cambridge University Press.

Coulson, S. (2001). Semantic Leaps. Frame-Shifting and Conceptual Blending in Meaning Construction. Cambridge: Cambridge University Press. doi: 10.1017/CBO9780511551352

Coulson, S. (2002). 'What's so funny: Conceptual blending in humorous examples'. Retrieved May 3, 2011 from http://www.cogsci.ucsd.edu/ coulson/funstuff/funny.html

Coulson, S. (2005). 'Extemporaneous blending: Conceptual integration in humorous discourse from talk radio'. Style 39, pp. 107-122.

Coulson, S., Urbach, T. P. \& Kutas, M. (2006). 'Looking back: Joke comprehension and the space structuring model'. Humor 19, pp. 229-250. doi: 10.1515/HUMOR.2006.013

Davies, C. (2005). 'European ethnic scripts and the translation and switching of jokes'. Humor 18 (2), pp. 147-160. DOI: 10.1515/humr.2005.18.2.147

Delibegović Džanić, N. \& Berberović, S. (2010). 'On politicians in big women's sunglasses driving buses with their feet in mouths: Late-night political humour and conceptual integration theory'. Jezikoslovlje 11 (2), pp. 197-214.

Retrieved November 21, 2012 from http://hrcak.srce.hr/file/94310

Delibegović Džanić, N. \& Berberović, S. (2017). '\#ForgiveUsForWeHaveSinned: Conceptual integration theory and political Internet humour', European Journal of Humour Research 5 (2), pp. 4-22. http://dx.doi.org/10.7592/EJHR2017.5.2.dzanic

Dynel, M. (2011). 'Blending the incongruity-resolution model and the conceptual integration theory: The case of blends in pictorial advertising'. International Review of Pragmatics 3 (1), pp. 59-83.

Eriksen, C. (2019). 'Negotiating adversity with humour: A case study of wildland firefighter women', Political Geography 68, pp. 139-145. https://doi.org/10.1016/j.polgeo.2018.08.001

Fauconnier, G. \& Turner, M. (1998). 'Blending as a central process of grammar: Expanded version' (March 1, 1998), in Goldberg, A. (ed.), Conceptual Structure, Discourse, and Language, Stanford: Center for the Study of Language and Information, pp. 113-130.

Fauconnier, G. \& Turner, M. (2002). The Way We Think: Conceptual Blending and the Mind's Hidden Complexities. New York: Basic Books.

Fauconnier, G. \& Turner, M. (2007). 'Conceptual integration networks', in Evans, V. et al. (eds.), The Cognitive Linguistics Reader, London: Equinox, pp. 360-419. 
Filipović-Kovačević, S. (2010). Indirektna komunikacija u reklamama na engleskom $i$ srpskom jeziku: kognitivnolingvistički pristup [Indirect Communication in English and Serbian Advertisements: A Cognitive Linguistic Approach]. Doctoral dissertation. Novi Sad: Filozofski fakultet.

Filipović-Kovačević, S. (2011). 'Anglicizmi kao međujezički pojmovni amalgami' [Anglicisms as interlinguistic conceptual blends]. Zbornik Matice srpske za filologiju $i$ lingvistiku 54(2), pp. 247-263.

Forceville, C. (2016). 'Mixing in pictorial and multimodal metaphors?', in Gibbs Jr., R.W. (ed.), Mixing Metaphor, Amsterdam: John Benjamins, pp. 223-239. doi: 10.1075/milcc.6.11for.

Grady, J., Oakley, T. \& Coulson, S. (1999). 'Blending and metaphor', in Steen, G. \& Gibbs, R.W. (eds.), Metaphor in Cognitive Linguistics, Amsterdam \& Philadelphia: John Benjamins, pp. 101-24.

Krikmann, A. (2006). 'Contemporary linguistic theories of humour'. Folklore 32, pp. 27-58. Retrieved January 17, 2011 from http://www.folklore.ee/folklore/vol33/kriku.pdf

Koestler, A. (1964). The Act of Creation. London: Hutchinson.

Kövecses, Z. (2006). Language, Mind, and Culture. A Practical Introduction. Oxford: Oxford University Press.

Lundmark, C. (2003). 'Puns and blending: The case of print advertisements'. Paper presented at the $8^{\text {th }}$ International Cognitive Linguistics Conference. Logroño, 20-25 July. Retrieved March 10, 2010 from http://wwwling.arts.kuleuven.ac.be/iclc/Papers/Lundmark.pdf.

Lyttle, J. B. (2001). The Effectiveness of Humor in Persuasion: the Case of Business Ethics Training. Doctoral Dissertation. Toronto: York University. Retrieved March 22018 from http://www.jimlyttle.com/PhD/Dissert2.html

Martin, R. A. (2007). The Psychology of Humor: An Integrative Approach. Amsterdam: Elsevier Academic Press.

Monro, D. H. (1963). Argument of Laughter. Notre Dame, IN: University of Notre Dame Press.

Monro, D. H. (1988). 'Theories of Humor', in Behrens, L. \& Rosen, L. J. (eds.), Writing and Reading Across the Curriculum ( $3^{\text {rd }}$ ed.), Glenview, IL: Scott, Foresman and Company, pp. 349-55. Retrieved February 20, 2018 from https://www.msu.edu/ jdowell/monro.html

Mulder, M. P. \& Nijholt, A. (2002). Humour Research: State of the Art. Technical report. CTIT. Twente: University of Twente.

Müller, C. \& Schmitt C. (2015). 'Audio-visual metaphors of the financial crisis: meaning making and the flow of experience', in Gibbs Jr., R.W. \& Corrêa Ferreira, L. (eds.), Revista Brasileira de Linguística Aplicada/Brazilian Journal of Applied Linguistics 15 (2) (Special Issue: Metaphor and Metonymy in Social Practices), pp. 311-341. http://dx.doi.org/10.1590/1984-639820156315

Nash, W. (1985). The Language of Humour. No. 16 in English Language series. Harlow: Longman.

Prodanović Stankić, D. (2016). Verbalni humor u engleskom i srpskom jeziku [Verbal Humour in English and Serbian]. Novi Sad: Filozofski fakultet.

Raskin, V. (1985). Semantic Mechanisms of Humor. Dordrecht: D. Reidel.

Raskin, V. (1998). 'From the editor', Humor 11 (1), pp. 1-4.

Rasulić, K. (2008). 'Srpsko-engleske tvorenice u svetlu teorije pojmovne integracije' [SerbianEnglish compounds in light of conceptual integration theory]. Semantička proučavanja srpskog jezika. Belgrade: SANU, pp. 269-289.

Rappoport, L. (2005). Punchlines: The Case for Racial, Ethnic, and Gender Humor. Westport, CT: Praeger. 
Schnell, Zs. (2007). 'Metaphor processing and the acquisition of idioms - a mentalistic model', Acta Linguistica 54 (1), pp. 73-104.

Schnell, Zs. (2012). 'The development of humour competence in Hungarian children - a cognitive approach', in T. Litovkina, A., Szőllősy, J., Medgyes, P., Brzozowska, D. (eds.), Hungarian Humour. Humor and Culture 3, Cracow: Tertium Society for the Promotion of Language Studies, pp. 235-251.

Schnell, Zs. \& Varga, E. (2012). 'Humour, irony and social cognition', in T. Litovkina, A., Szőllősy, J., Medgyes, P., Chłopicki, W. (eds.), Hungarian Humour. Humor and Culture 3, Cracow: Tertium Society for the Promotion of Language Studies, pp. 253-270.

Smuts, A. (2006). 'Humor', in Schneider, S. J. (ed.), Internet Encyclopedia of Philosophy. Retrieved February 1, 2011 from http://www.iep.utm.edu/humor/

Suls, J. (1972). 'A two-stage model for the appreciation of jokes and cartoons', in Goldstein J. H. \& McGhee, P. E. (eds.), The Psychology of Humor: Theoretical Perspectives and Empirical Issues, New York: Academic Press, pp. 81-100.

Tabacaru, S. \& Lemmens, M. (2014). 'Raised eyebrows as gestural triggers in humour: The case of sarcasm and hyper-understanding' European Journal of Humour Research 2(2). 11-31.doi:10.7592/EJHR2014.2.2.tabacaru

Turner, M. (2015). 'Blending in language and communication', in Dąbrowska, E. \& Divjak, D. (eds.), Handbook of Cognitive Linguistics, Berlin: Mouton de Gruyter, pp. 211-232.

Veale, T., Feyaerts, K. \& Brône, G. (2006). 'The cognitive mechanisms of adversarial humor'. Humor 19 (3), pp. 305-339. doi:10.1515/HUMOR.2006.016

Wijewardena, N., Härtel, C.E.J. \& Samaratunge, R. (2010). 'Chapter 10: A laugh a day is sure to keep the blues away: managers' use of humor and the construction and destruction of employees' resilience', in Zerbe, W. J., Härtel C. E. J. \& Ashkanasy N. M. (eds.), Emotions and Organizational Dynamism (Research on Emotion in Organizations, Volume 6), Bingley, UK: Emerald Group Publishing, pp. 259-278.

Yus, F. (2016). Humour and Relevance. Amsterdam: John Benjamins.

\section{Joke Sources}

(1) https://www.mathisfunforum.com/viewtopic.php?pid=406920; Retrieved May 13, 2017.

(2) https://unijokes.com/joke-3890/; Retrieved May 11, 2017.

(3) http://jokesallday.com/what-does-woody-allen-call-an-unborn-baby; Retrieved May 11, 2017.

(4) http://www.jokes2go.com/jokes/25342.html; Retrieved May 11, 2017.

(5) https://unijokes.com/joke-7355/; Retrieved May 12, 2017.

(6) http://www.jokes2go.com/jokes/25318.html; Retrieved May 10, 2017.

(7) https://jokes.one/joke/what-do-you-get-if-you-cross-a-black-person-with-an-octopus; Retrieved January 19, 2018.

(7a) Stojadinović, A. (2009). Ex Yu antologija viceva [Ex-Yugoslav Joke Anthology]. Beograd: Logos Art, p. 325.

(8) https://www.najboljivicevi.com/vic.php?id=2540; Retrieved January 20, 2018.

(9) https://www.najboljivicevi.com/vic.php?id=2149; Retrieved January 20, 2018.

(10) http://www.knjigaviceva.com/3445/sta-je-bolje-od-red-bula/; Retrieved January 22, 2018.

(11) http://www.vicevi-dana.com/vicevi-Kako-se-zove-Cecin-doktor-br-/201106013; Retrieved January 25, 2018.

(12) https://www.vicevi.rs/vicevi/svastara/brus-vilis; Retrieved January 20, 2018. 